\title{
Prognostic impact of pathological complete remission after preoperative irradiation in patients with locally advanced head and neck squamous cell carcinoma: re-analysis of a phase 3 clinical study
}

Kai Wang ${ }^{1}$, Junlin $\mathrm{Yi}^{1^{*}} \mathbb{0}$, Xiaodong Huang ${ }^{1}$, Yuan $\mathrm{Qu}^{1}$, Jingwei Luo ${ }^{1}$, Jianping Xiao ${ }^{1}$, Shiping Zhang ${ }^{1}$, Yuan Tang ${ }^{1}$,

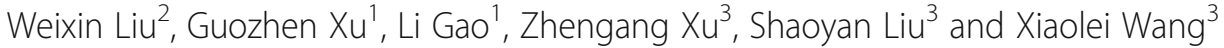

\begin{abstract}
Purpose: The purpose of this study was to determine the associations between pathological complete remission (pCR) and clinical outcomes in patients with locally advanced head and neck squamous cell carcinoma (HNSCC) who received preoperative radiotherapy or chemoradiotherapy in a phase 3 clinical study.

Methods: A total of 222 newly diagnostic stage III/IVMO HNSCC patients were randomly assigned to a preoperative concurrent chemoradiotherapy group $(n=104)$ or preoperative radiotherapy alone group $(n=118)$. Over a mean follow-up of 59 months, 72 patients were defined as non-responders to preoperative therapy and subsequently underwent resection of the primary lesion with or without neck dissection. The relationship between the pathological tumor response of the primary lesion and treatment prognosis was analyzed. Kaplan-Meier and Cox regression multivariate analyses were performed to evaluate the impact of pCR on local control (LC), overall survival (OS), progression-free survival (PFS), and distant metastasis-free survival (DMFS).

Results: Among the 72 non-responders, 25 patients, 10 in the chemotherapy group and 15 in the radiotherapy group, achieved pCR. The 5-year LC, OS, PFS, and DMFS of pCR patients and non-pCR patients were $93.2 \%$ vs. $67.7 \%$ $(p=0.007), 83.3 \%$ vs. $39.7 \%$ ( $p=0.0006), 76.1 \%$ vs. $44.0 \%(p=0.009)$, and $90.4 \%$ vs. $56.3 \%(p=0.005)$, respectively. In multivariate analysis, $\mathrm{pCR}$ is also an independent prognostic factor in prognosis, with statistically significant differences.
\end{abstract}

Conclusion: $\mathrm{PCR}$ after preoperative radiotherapy or concurrent chemoradiotherapy is a good prognostic factor in locally advanced HNSCC.

Trial registration: Number:ChiCTR-TRC-114004322

Date:05 Mar, 2014

Keywords: Head and neck squamous cell carcinoma, Preoperative radiotherapy, Concurrent chemoradiotherapy, Pathological complete remission, Prognosis

\footnotetext{
* Correspondence: yijunlin1969@163.com

'Department of Radiation Oncology, National Cancer Center/Cancer Hospital,

Chinese Academy of Medical Sciences and Peking Union Medical College,

Beijing, China

Full list of author information is available at the end of the article
}

C The Author(s). 2019 Open Access This article is distributed under the terms of the Creative Commons Attribution 4.0 International License (http://creativecommons.org/licenses/by/4.0/), which permits unrestricted use, distribution, and 


\section{Introduction}

Although surgery followed by radiotherapy and/or concurrent chemoradio- therapy has been the major treatment choice recommended by the NCCN guideline for treating locally advanced head and neck squamous cell carcinoma (HNSCC) for many years [1], the outcome with this regimen is still limited by a low 5 -year survival rate, which remains $<40 \%[2,3]$. In recent years, several researches have suggested that preoperative radiotherapy and preoperative concurrent chemoradiotherapy may improve the overall survival (OS) compared to surgery alone in patients with head and neck cancer [4-6]. The advantages of preoperative radiotherapy or preoperative concurrent chemoradiotherapy for head and neck cancer include down-staging, increased resectability rate, etc. Further evidence from several phase 2 studies have shown that preoperative concurrent chemoradiotherapy provides excellent treatment outcomes by leading to a pathological complete response rate ranging from 35 to $61 \%$ and an increased 5-year OS rate of up to 70-81.5\% [5-8].

Several authors have suggested that the pathological response to preoperative radiotherapy or chemoradiotherapy is a valuable prognostic factor for local control and OS $[9,10]$. In one of our randomized phase 3 studies, we evaluated the role of adding concurrent cisplatin to preoperative radiotherapy in the treatment of locally advanced HNSCC [11]. In this study, 222 eligible patients were randomly assigned to a preoperative radiotherapy group $(n=118)$ or a preoperative concurrent chemoradiotherapy group $(n=104)$. The results revealed that preoperative concurrent chemoradiotherapy led to a significantly improved distant metastasis-free survival (DMFS) compared to preoperative radiotherapy alone. According to the protocol, non-responders (defined by $<80 \%$ reduction of the primary lesion after preoperative treatment), subsequently underwent resection of the primary lesion with or without neck dissection depending on the nodal status. In total, 72 non-responders (33.8\%) were observed in this phase 3 study.

In the present study, we analyzed the relationships between pathological complete remission (pCR) and clinical outcomes in these 72 non-responder patients.

\section{Materials and methods \\ Patients}

The details of the study design and data collection have been published in our previous study [11]. In brief, from September 2002 to May 2012, a total of 222 HNSCC patients were enrolled in this phase 3 study, among which 104 patients were assigned to the preoperative concurrent chemoradiotherapy group and 118 patients were assigned to the preoperative radiotherapy group.

\section{Treatment}

All these patients received radiotherapy with either twodimensional or intensity-modulated radiotherapy (IMRT). Patients assigned to the chemoradiotherapy group additionally received concurrent chemotherapy with $30 \mathrm{mg} /$ $\mathrm{m}^{2}$ cisplatin weekly. The tumor response was assessed by computed tomography (CT) and/or magnetic resonance imaging (MRI) and endoscopy examination at the end of the 5th week (50 Gy). Non-responders (defined as < $80 \%$ reduction of the primary lesion volume) underwent resection of the primary tumor and modified neck dissection within 4-6 weeks after the completion of preoperative treatment. Seventy-two patients were non-responders, including 35 patients in the preoperative radiotherapy group and 37 patients in the chemoradiotherapy group.

\section{Pathological response analysis}

The surgical samples of all clinical non-responders were assessed pathologically, and patients were classified according to the pathological response as the $\mathrm{PCR}$ group and non-pCR group, depending on whether residual tumor cells remained in the surgical sample or not.

\section{Follow-up}

After completion of the treatment plan, patients were followed up for a minimum of 5 years or until death, with a regular frequency: at 1 month, every 3 months for the first 2 years, every 6 months for the 2-5 years after treatment, and every year thereafter.

\section{Statistical analysis}

In our previous study, we revealed that in a subset of patients with primary tumors of the larynx-hypopharynx, preoperative chemoradiotherapy significantly improved the PFS and DMFS, and also provided a borderline benefit in OS in compared with preoperative radiotherapy. Therefore, in the current study, a sub-analysis comparing clinical outcomes in patients with larynxhypopharynx primary tumors was performed.

Log-rank test was applied to compare the differences in baseline characteristics between $\mathrm{pCR}$ and non-pCR patients. The LC, OS, PFS and DMFS were calculated by the Kaplan-Meier method. The multivariate analysis were by Cox regressive analysis. All tests were two-sided and $p<0.05$ was considered statistically significant. All analyses were conducted using SPSS 21.0 software (IBM Corporation, Armonk, New York, U.S).

\section{Results}

Baseline characteristic between different pathological responses

The total of 72 non-responders included 37 patients in the preoperative concurrent chemoradiotherapy group $(n=$ $104)$ and 35 patients in the preoperative radiotherapy group 
( $n=118$ ). Among these 72 non-responders, 25 patients (34.7\%) achieved pCR, including 10 patients (10/37) in the chemoradiotherapy group and 15 patients $(15 / 25)$ in the radiotherapy group (Table 1). There were no significant differences between the $\mathrm{pCR}$ and non-pCR groups in terms of primary tumor site, tumor staging ( $\mathrm{T}, \mathrm{N}$ stage), grades of clinical group, and treatment technique (all $p>0.05$ ).

\section{Univariate analysis of prognostic impact of $\mathrm{pCR}$ for treatment outcomes}

Over a median follow-up of 24 months (range, 3-122 months), the 5-year estimated LC, OS, PFS, and DMFS

Table 1 Baseline characteristics of 72 patients with locally advanced head and neck squamous cell carcinoma according to whether they achieved pathological complete remission (pCR)

\begin{tabular}{|c|c|c|c|c|c|}
\hline \multirow[t]{2}{*}{ Characteristic } & \multicolumn{2}{|c|}{$\mathrm{pCR}(n=25)$} & \multicolumn{2}{|c|}{ Non-pCR $(n=47)$} & \multirow{2}{*}{$\begin{array}{l}p- \\
\text { value }\end{array}$} \\
\hline & $\mathrm{n}$ & $\%$ & $\mathrm{n}$ & $\%$ & \\
\hline \multicolumn{6}{|l|}{ Gender } \\
\hline Male & 22 & 35.5 & 40 & 64.5 & \multirow[t]{3}{*}{0.735} \\
\hline Female & 3 & 30.0 & 7 & 70.0 & \\
\hline Median age (years) & 55 & & 55 & & \\
\hline \multicolumn{6}{|l|}{ Primary site } \\
\hline Oral cavity & 4 & 30.8 & 9 & 69.2 & \multirow[t]{3}{*}{0.869} \\
\hline Oropharynx & 4 & 30.8 & 9 & 69.2 & \\
\hline Larynx/Hypopharynx & 17 & 37.0 & 29 & 63.0 & \\
\hline \multicolumn{6}{|l|}{ T stage } \\
\hline $\mathrm{T} 1$ & 1 & 50.0 & 1 & 50.0 & \multirow[t]{5}{*}{0.218} \\
\hline $\mathrm{T} 2$ & 7 & 63.6 & 4 & 36.4 & \\
\hline T3 & 7 & 35.0 & 13 & 65.0 & \\
\hline T4a & 9 & 26.5 & 25 & 73.5 & \\
\hline $\mathrm{T} 4 \mathrm{~b}$ & 1 & 20.0 & 4 & 80.0 & \\
\hline \multicolumn{6}{|l|}{ N stage } \\
\hline NO & 2 & 25.0 & 6 & 75.0 & \multirow[t]{4}{*}{0.266} \\
\hline N1 & 1 & 10.0 & 9 & 90.0 & \\
\hline N2 & 18 & 40.9 & 26 & 59.1 & \\
\hline N3 & 4 & 40.0 & 6 & 60.0 & \\
\hline \multicolumn{6}{|l|}{ Clinical group } \\
\hline III & 1 & 14.3 & 6 & 85.7 & \multirow[t]{3}{*}{0.463} \\
\hline IVA & 9 & 22.5 & 31 & 77.5 & \\
\hline IVB & 5 & 33.3 & 10 & 66.7 & \\
\hline \multicolumn{6}{|l|}{ Concurrent chemotherapy } \\
\hline Yes & 10 & 27.0 & 27 & 73.0 & \multirow[t]{2}{*}{0.158} \\
\hline No & 15 & 42.9 & 20 & 57.1 & \\
\hline \multicolumn{6}{|l|}{ Radiotherapy technique } \\
\hline $2 \mathrm{D}$ & 14 & 29.8 & 33 & 70.2 & \multirow[t]{2}{*}{0.228} \\
\hline IMRT & 11 & 44.0 & 14 & 56.0 & \\
\hline
\end{tabular}

2D Two dimensional, IMRT Intensity-modulated radiotherapy for $\mathrm{pCR}$ patients and non-pCR patients were $93.2 \%$ vs. $67.7 \%(p=0.007), 83.3 \%$ vs. $39.7 \%(p=0.0006), 76.1 \%$ vs. $44.0 \%(p=0.003)$, and $90.4 \%$ vs. $56.3 \%(p=0.005)$, respectively (Fig. 1).

There were 46 non-responders with larynxhypopharynx primary tumors, 17 of whom achieved pCR of the primary lesion. The 5-year estimated LC, OS, PFS, and DMFS for these $\mathrm{pCR}$ and non-pCR patients were $100 \%$ vs. $81.4 \%(p=0.068), 94.7 \%$ vs. $50.1 \%(p=0.008)$, $81.9 \%$ vs. $51.2 \%(p=0.03)$, and $94.1 \%$ vs. $61.1 \%(p=$ 0.02 ), respectively (Fig. 2 ).

\section{Multivariate analysis of prognostic impact of pCR for treatment outcomes}

In multivariate analysis, $\mathrm{pCR}$ was an independent prognostic factors of $\operatorname{LC}(p=0.002)$ (Table 2) and OSwith statistically significant differences $(\mathrm{p}<0.001)$ (Table 3$)$. And pCR also played an significant role in DMFS and PFS (Additional file 1: Table S1). In addition, the degree of pathological differentiation, primary lesion in hypopharynx/larynx and $\mathrm{N}$ stage were also independent prognostic factors for OS. Other factors such as gender, age, $\mathrm{T}$ stage, technology of radiation and chemotherapy were not independent prognostic factors for OS.

\section{Discussion}

The current analysis revealed that clinical outcomes including local control, OS, PFS, and DMFS were statistically better in patients with locally advanced HNSCC who achieved pCR than in those who did not. These results indicate that $\mathrm{pCR}$ could be used as a potential prognostic factor for patients with locally advanced HNSCC after preoperative irradiation.

Non-response after preoperative treatment was defined by a reduction in the primary lesion of less than $80 \%$ at the end of $50 \mathrm{~Gy}$ irradiation with or without chemotherapy as evaluated by CT/MRI and endoscopy examination. We identified 25 out of 72 (34.7\%) patients who achieved pCR among those who were nonresponders to preoperative treatment. In the study by Kirita et al. [12], 48 patients with oral cavity cancer received cisplatin- or carboplatin-based preoperative concurrent chemoradiotherapy (RT 40 Gy), and the clinical $\mathrm{CR}$ and pCR rates were 60.4 and $50 \%$, respectively. The lower pCR rate found in our study can primarily be attributed to the fact that only non-responding patients received surgical treatment in our study. In our phase 3 study, of the 222 patients enrolled, only 72 were nonresponders based on imaging examination after 50 Gy irradiation with or without chemotherapy and underwent surgery. The other 150 patients who showed a good response received non-surgical therapy, and it is reasonable to expect that if they had been treated with surgery, 

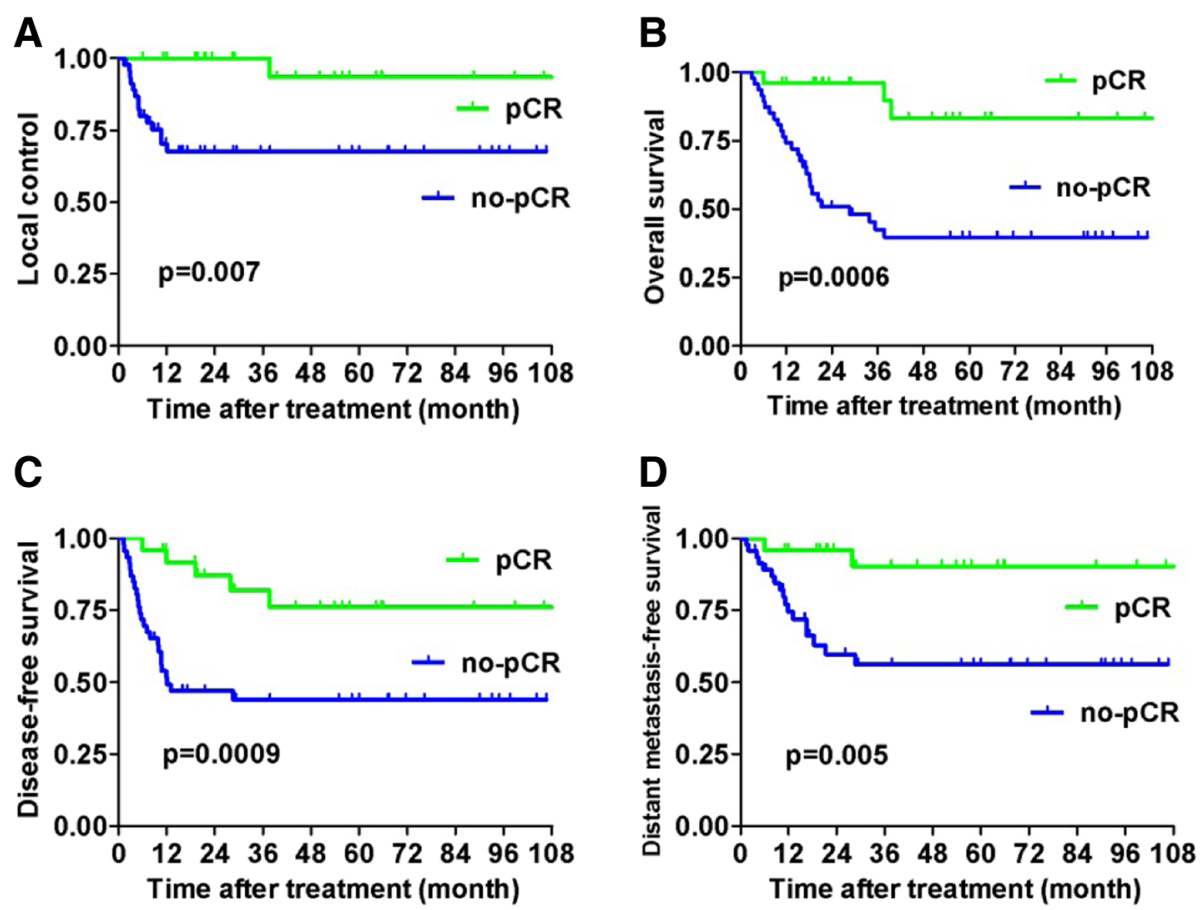

Fig. 1 Differences in treatment outcomes between pCR and non-pCR patients among the whole cohort of patients: a local control, b overall survival, c progression-free survival, and $\mathbf{d}$ distant metastasis-free survival
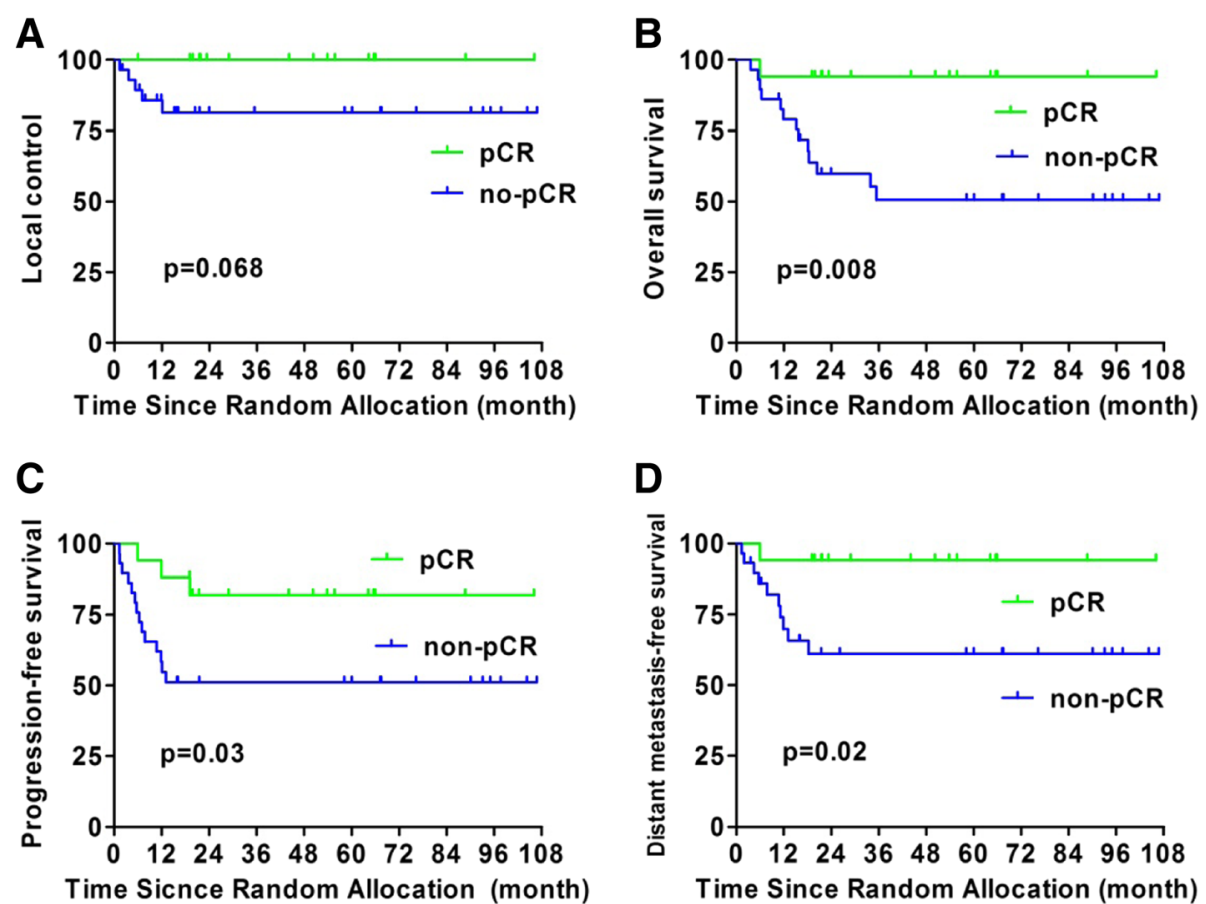

Fig. 2 Differences in treatment outcomes between the pCR and non-pCR patients who had primary tumors of the larynx-hypopharynx: a local control, b overall survival, $\mathbf{c}$ progression-free survival, and $\mathbf{d}$ distant metastasis-free survival 
Table 2 Multivariate analysis for the local control

\begin{tabular}{|c|c|c|c|c|c|}
\hline & & B & SE & $\mathrm{p}$ & $\mathrm{HR}(95 \% \mathrm{Cl})$ \\
\hline Gender & male vs female & -.181 & .702 & 0.797 & $0.835(0.211-3.304)$ \\
\hline Age & $\leq 55$ vs $>55$ & 1.263 & .730 & 0.084 & $3.535(0.845-14.792)$ \\
\hline Primary site & $\begin{array}{l}\text { hypopharyngeal carcinoma/laryngeal carcinoma } \\
\text { vs other primary sites }\end{array}$ & 3.114 & .847 & 0.000 & $22.503(4.279-118.346)$ \\
\hline Degree of pathological differentiation & Well/modarate vs poor differentiaon / undifferentiation & 3.036 & .914 & 0.001 & $20.828(3.476-124.821)$ \\
\hline T stage & T4 vs T1-3 & -1.782 & .757 & 0.019 & $0.168(0.038-0.743)$ \\
\hline N stage & No vs N1-2 vs N3 & 2.445 & .809 & 0.003 & $11.527(2.361-56.271)$ \\
\hline Technology of radiation & $2 \mathrm{D}$ vs IMRT & .334 & .971 & 0.731 & $1.396(0.208-9.359)$ \\
\hline Chemotherapy & No vs Yes & -.182 & .592 & 0.758 & $0.833(0.261-2.662)$ \\
\hline $\mathrm{pCR}$ & Yes vs No & 4.004 & 1.290 & 0.002 & 54.839 (4.373-687.660) \\
\hline
\end{tabular}

the $\mathrm{pCR}$ rate would be higher in the 150 good responders than in the 72 non-responders.

Although planned preoperative concurrent chemoradiotherapy in head and neck cancer is not as popular as in esophageal cancer, rectal cancer, breast cancer, and non-small cell lung cancer, the relationship between pathological response and clinical outcome after preoperative radiotherapy has also been well studied. Friesland et al. [13] reported that among 167 patients with tonsillar carcinoma treated by radiotherapy with or without surgery, $28 \%$ of patients received surgery for the primary site and/or neck dissection after radiotherapy, and the 5-year OS for patients with pCR was $43 \%$, whereas that for patients with non-pCR was $9 \%(p<0.0001)$. The long-term prognostic value of achieving clinical $C R$, especially $\mathrm{pCR}$ in oral cancer was reported by Kirita et al [12], who found that the 10-year PFS of patients with pCR was better than that of patients with extensive residual tumor ( $87.5 \%$ vs. $40 \%$ ). In addition, patients who showed good histopathology responses had superior survival $(p=0.012)$. The same results were found in patients with tongue carcinoma [14]; the PFS rates according to tumor regression rate were $33.3 \%$ for patients with less than $50 \%$ tumor regression, $66.7 \%$ for patients with 50
$75 \%$ regression, $100 \%$ for patients with $75-100 \%$ regression, and $96.0 \%$ for patients with complete regression. The survival rate was statistically different between patients who achieved a regression rate of $75 \%$ or higher and those who did not $(p<0.0001)$. Other authors also reported significant differences in treatment outcomes between good and poor responders, with 5-year survival rates of $68-84 \%$ versus $24-32 \%[10,15]$.

Recently, preoperative concurrent chemoradiotherapy has been used increasingly more frequently in esophagogastric cancer, non-small cell lung cancer, rectal cancer, and breast cancer, and it was found that a good pathologic response to preoperative chemoradiotherapy correlates with better long-term survival in these cancers [16-25]. Even in resectable non-small cell lung cancer, the major pathological response was suggested to be a surrogate endpoint for survival in future neoadjuvant trials [23]. Based on the results obtained in studies of esophagogastric cancer and rectal cancer, planned preoperative concurrent chemoradiotherapy may play an important role in the treatment of locally advanced head and neck cancer.

The relationship between clinical response and pathological response is still controversial. In our study, 25

Table 3 Multivariate analysis for the overall survival

\begin{tabular}{|c|c|c|c|c|c|}
\hline & & B & SE & $\mathrm{p}$ & HR $(95 \% \mathrm{Cl})$ \\
\hline Gender & male vs female & -.816 & .561 & 0.146 & $0.442(0.147-1.327)$ \\
\hline Age & $\leq 55$ vs $>55$ & .359 & .425 & 0.399 & $1.431(0.622-3.294)$ \\
\hline Primary site & $\begin{array}{l}\text { hypopharyngeal carcinoma/laryngeal carcinoma } \\
\text { vs other primary sites }\end{array}$ & 1.024 & .431 & 0.018 & $2.783(1.196-6.476)$ \\
\hline Degree of pathological differentiation & Well/modarate vs poor differentiaon / undifferentiation & 1.833 & .543 & 0.001 & $6.254(2.157-18.129)$ \\
\hline T stage & T4 vs T1-3 & .406 & .441 & 0.357 & $1.501(0.633-3.564)$ \\
\hline N stage & N0 vs N1-2 vs N3 & 1.511 & .489 & 0.002 & $4.532(1.737-11.824)$ \\
\hline Technology of radiation & $2 \mathrm{D}$ vs IMRT & -.256 & .572 & 0.654 & $0.774(0.252-2.376)$ \\
\hline Chemotherapy & No vs Yes & -.596 & .419 & 0.155 & $0.551(0.242-1.252)$ \\
\hline $\mathrm{pCR}$ & Yes vs No & 2.460 & .694 & 0.000 & $11.71(3.003-45.663)$ \\
\hline
\end{tabular}


(34.7\%) clinical non-responders' achieved pCR for the primary lesion. For gastric-esophagus conjunction carcinoma, Cheedella et al. [18] reported that the specificity of clinical CR for pCR is too low to be used for clinical decision-making regarding the delay or avoidance of surgery. The same finding was reported in rectal cancer treated with preoperative chemoradiotherapy [26]. Accurately predicting $\mathrm{pCR}$ after preoperative treatment and thereby avoiding surgery is difficult. This issue has been the focus of many efforts in recent years, and functional imaging has been suggested to resolve this problem. Hatakenaka et al. [27] found that pretreatment apparent diffusion coefficient (ADC) of the primary lesion correlated with local failure in 38 primary HNSCC patients treated with chemoradiotherapy or radiotherapy. Vandecaveye et al. [28] compared the change in ADC between before and 3 weeks after CRT ( $\triangle \mathrm{ADC}$ ) in 29 HNSCC patients and found that the negative predictive value of $\triangle \mathrm{ADC}$ in terms of tumor response for the primary lesion was $100 \%$, and diffusion-weighted imaging (DWI) was better than anatomical imaging in predicting tumor response. Jacobs et al. [29] also found that the $\triangle \mathrm{ADC}$ during chemoradiotherapy and 4 weeks postchemoradiotherapy were the best predictive parameters for pathological good response. Ceulemans et al. [30] investigated the role of fluorodeoxy glucose positron emission tomography PET/CT during radiotherapy (47 Gy) and 4 months after radiotherapy in 40 HNSCC patients and found that PET/CT at both times had a high specificity and positive predictive value for the evaluation of tumor response, suggesting that it might be used as an indicator for avoiding unnecessary salvage surgery in patients with $\mathrm{CR}$, although $\mathrm{PET} / \mathrm{CT}$ at 4 months after radiotherapy had the strongest predictive power. Hur et al. [31] reported a biomarker-based scoring system for predicting tumor response after preoperative chemoradiotherapy in rectal cancer. They found that the mRNA expression levels of four biomarkers (p53, p21, Ki67, and CD133) significantly correlated with tumor regression grade and pathologic complete response. Radiogenomics, which links different imaging features with diverse genomic events, is a new and exciting field within radiology, and imaging genomic linkages can help in monitoring treatment response. This method now is widely investigated in many types of tumors such as brain tumor, rectal cancer, and head and neck cancer [32, 33].

In summary, for locally advanced HNSCC, a multidisciplinary treatment modality was the mainstay treatment choice. Achievement of $\mathrm{pCR}$ after preoperative treatment is associated with good treatment outcomes. At present, induction chemotherapy followed by concurrent chemoradiotherapy or concurrent chemoradiotherapy, with surgery as salvage therapy, is used with increasing frequency in the treatment of locally advanced HNSCC.
Determining how to assess the tumor response accurately after preoperative treatment is very important, and for patients who achieved pCR, surgery may be avoidable, which improves organ function preservation. Moreover, it is reasonable to expect that the tumor response after preoperative treatment will help to predict outcome even more accurately when combined with clinical characteristics based on functional imaging, biomarkers, and genomics.

\section{Supplementary information}

Supplementary information accompanies this paper at https://doi.org/10. 1186/s13014-019-1428-4.

Additional file 1: Table S1. Multivariate analysis for DMFS and PFS.

\section{Abbreviation}

2D: Two dimensional; ADC: Apparent diffusion coefficient; CR: Complete remission; CT: Computed tomography; DMFS: Distant metastasis-free survival; DWI: Diffusion-weighted imaging; HNSCC: Head and neck squamous cell carcinoma; IMRT: Intensity-modulated radiotherapy; LC: Local control; MRI: Magnetic resonance imaging; mRNA: messenger RNA; NCCN: National Comprehensive Cancer Network; OS: Overall survival; pCR: pathological complete remission; PET: Positron emission tomography; PFS: Progressionfree survival

\section{Acknowledgements}

The authors thank all patients who participated in the present study.

\section{Authors' contributions}

All authors listed have made a substantial, direct and intellectual contribution to the work, and approved it for publication. All authors have read and approved the final manuscript. Conception and design: JY, LG, ZX Administrative support: LG. Provision of study materials or patients: KW, JY, $X H, Z X, S L, X W, J L, J X, S Z, Y Q, Y T, W L, G X, L G$. Collection and assembly of data: JY, XH, SL, YT, WL, LG. Data analysis and interpretation: KW, JY, LG. Manuscript writing: KW, JY, LG.

\section{Funding}

This study was supported by The National Key R\&D Program of China (2017YFC0107500).

\section{Availability of data and materials}

The datasets used and/or analyzed during the current study are available from the corresponding author on reasonable request.

\section{Ethics approval and consent to participate}

This is re-analysis of a phase 3 clinical study. The prospective study was approved by National Cancer Center/Cancer Hospital, Chinese Academy of Medical Science and Peking Union Medical College (No.CAMSCHRTOG20021) Institutional Review Board. All patients provided written informed consent prior to treatment, and all information was anonymized prior to analysis.

\section{Consent for publication}

Not applicable.

\section{Competing interests}

The authors declare that they have no competing interests.

\section{Author details}

${ }^{1}$ Department of Radiation Oncology, National Cancer Center/Cancer Hospital, Chinese Academy of Medical Sciences and Peking Union Medical College, Beijing, China. ${ }^{2}$ Department of Radiation Oncology, Peking University Cancer Hospital and Institute, Beijing, China. ${ }^{3}$ Department of Head and Neck Surgery, National Cancer Center/Cancer HospitalChinese Academy of Medical Sciences and Peking Union Medical College, Beijing, China. 
Received: 12 May 2019 Accepted: 22 November 2019

Published online: 12 December 2019

\section{References}

1. Pfister DG, Ang K, Brockstein B, Colevas AD, Ellenhorn J, Goepfert H, et al. NCCN practice guidelines for head and neck cancers. Oncology (Williston Park). 2000;14(11A):163-94.

2. Kramer S, Gelber RD, Snow JB, Marcial VA, Lowry LD, Davis LW, et al. Combined radiation therapy and surgery in the management of advanced head and neck cancer: final report of study 73-03 of the radiation therapy oncology group. Head Neck Surg. 1987;10(1):19-30.

3. Jesse $\mathrm{RH}$, Fletcher $\mathrm{GH}$. Treatment of the neck in patients with squamous cell carcinoma of the head and neck. Cancer. 1977;39(2 Suppl):868-72.

4. Mucke T, Konen M, Wagenpfeil S, Kesting MR, Wolff KD, Holzle F. Low-dose preoperative chemoradiation therapy compared with surgery alone with or without postoperative radiotherapy in patients with head and neck carcinoma. Ann Surg Oncol. 2011;18(10):2739-47.

5. del Campo JM, Felip E, Giralt J, Raspall G, Bescos S, Casado S, et al. Preoperative simultaneous chemoradiotherapy in locally advanced cancer of the oral cavity and oropharynx. Am J Clin Oncol. 1997;20(1):97-100.

6. Giralt JL, Gonzalez J, del Campo JM, Maldonado J, Sanz X, Pamias J, et al. Preoperative induction chemotherapy followed by concurrent chemoradiotherapy in advanced carcinoma of the oral cavity and oropharynx. Cancer. 2000;89(5):939-45.

7. Kirita T, Ohgi K, Tsuyuki M, Kamikaido N, Yamamoto K, Sugimura M. Preoperative simultaneous cisplatin- or carboplatin-based chemotherapy and radiotherapy for squamous cell carcinoma of the oral cavity. J Surg Oncol. 1996;63(4):240-8.

8. Kirita T, Yamanaka Y, Imai Y, Yamakawa N, Aoki K, Nakagawa Y, et al. Preoperative concurrent chemoradiotherapy for stages II-IV oral squamous cell carcinoma: a retrospective analysis and the future possibility of this treatment strategy. Int J Oral Maxillofac Surg. 2012;41(4):421-8.

9. Klug C, Berzaczy D, Voracek M, Millesi W. Preoperative chemoradiotherapy in the management of oral cancer: a review. J Cranio-maxillo-facial Surg. 2008;36(2):75-88.

10. Onizawa K, Yoshida H, Ohara K, Noguchi M. Predictive factors for the histologic response to preoperative radiotherapy in advanced oral cancer. J Oral Maxillofac Surg. 2006;64(1):81-6.

11. Yi J, Huang $X, X u Z$, Liu S, Wang $X$, He $X$, et al. Phase III randomized trial of preoperative concurrent chemoradiotherapy versus preoperative radiotherapy for patients with locally advanced head and neck squamous cell carcinoma. Oncotarget. 2017:8(27):44842-50.

12. Kirita T, Ohgi K, Shimooka H, Yamanaka Y, Tatebayashi S, Yamamoto K, et al. Preoperative concurrent chemoradiotherapy plus radical surgery for advanced squamous cell carcinoma of the oral cavity: an analysis of longterm results. Oral Oncol. 1999;35(6):597-606.

13. Friesland S, Fernberg JO, Lundell G, Munck-Wikland E, Strander H, Lewensohn R. Prognostic impact of complete remission after preoperative irradiation of tonsillar carcinoma: a retrospective analysis of the radiumhemmet data, 19801995. Int J Radiat Oncol Biol Phys. 1999;45(5):1259-66.

14. Kirita T, Shimooka H, Yamanaka Y, Tatebayashi S, Yamamoto K, Nishimine M et al. Prognostic value of response to preoperative chemoradiotherapy and residual tumor grades in tongue carcinoma. Oral Surg Oral Med Oral Pathol Oral Radiol Endod. 2001;91(3):293-300.

15. Brun E, Zatterstrom U, Kjellen E, Wahlberg P, Willen R, Brun A, et al. Prognostic value of histopathological response to radiotherapy and microvessel density in oral squamous cell carcinomas. Acta Oncol. 2001;40(4):491-6.

16. Homann N, Pauligk C, Luley K, Werner Kraus T, Bruch HP, Atmaca A, et al. Pathological complete remission in patients with oesophagogastric cancer receiving preoperative 5-fluorouracil, oxaliplatin and docetaxel. Int J Cancer. 2012;130(7):1706-13

17. Lowy AM, Mansfield PF, Leach SD, Pazdur R, Dumas P, Ajani JA. Response to neoadjuvant chemotherapy best predicts survival after curative resection of gastric cancer. Ann Surg. 1999;229(3):303-8.

18. Cheedella NK, Suzuki A, Xiao L, Hofstetter WL, Maru DM, Taketa T, et al. Association between clinical complete response and pathological complete response after preoperative chemoradiation in patients with gastroesophageal cancer: analysis in a large cohort. Ann Oncol. 2013;24(5):1262-6.

19. Lorenzen S, Thuss-Patience P, Al-Batran SE, Lordick F, Haller B, Schuster T, et al. Impact of pathologic complete response on disease-free survival in patients with esophagogastric adenocarcinoma receiving preoperative docetaxel-based chemotherapy. Ann Oncol. 2013;24(8):2068-73.
20. Fokas E, Liersch T, Fietkau R, Hohenberger W, Beissbarth T, Hess C, et al. Tumor regression grading after preoperative chemoradiotherapy for locally advanced rectal carcinoma revisited: updated results of the CAO/ARO/AIO94 trial. J Clin Oncol. 2014;32(15):1554-62.

21. Abdul-Jalil KI, Sheehan KM, Kehoe J, Cummins R, O'Grady A, McNamara DA, et al. The prognostic value of tumour regression grade following neoadjuvant chemoradiation therapy for rectal cancer. Color Dis. 2014;16(1):016-25.

22. Ayloor Seshadri R, Kondaveeti SS, Jayanand SB, John A, Rajendranath $R$, Arumugam $V$, et al. Complete clinical response to neoadjuvant chemoradiation in rectal cancers: can surgery be avoided? Hepatogastroenterology. 2013;60(123):410-4.

23. Hellmann MD, Chaft JE, William WN Jr, Rusch V, Pisters KM, Kalhor N, et al. Pathological response after neoadjuvant chemotherapy in resectable nonsmall-cell lung cancers: proposal for the use of major pathological response as a surrogate endpoint. Lancet Oncol. 2014;15(1):e42-50.

24. Guiu S, Arnould L, Bonnetain F, Dalban C, Favier L, Desmoulins I, et al. Pathological response and survival after neoadjuvant therapy for breast cancer: a 30-year study. Breast. 2013;22(3):301-8.

25. Kong X, Moran MS, Zhang N, Haffty B, Yang Q. Meta-analysis confirms achieving pathological complete response after neoadjuvant chemotherapy predicts favourable prognosis for breast cancer patients. Eur J Cancer. 2011; 47(14):2084-90.

26. Smith FM, Wiland $H$, Mace A, Pai RK, Kalady MF. Clinical criteria underestimate complete pathological response in rectal cancer treated with neoadjuvant chemoradiotherapy. Dis Colon Rectum. 2014;57(3):311-5.

27. Hatakenaka M, Nakamura K, Yabuuchi H, Shioyama Y, Matsuo Y, Ohnishi K, et al. Pretreatment apparent diffusion coefficient of the primary lesion correlates with local failure in head-and-neck cancer treated with chemoradiotherapy or radiotherapy. Int J Radiat Oncol Biol Phys. 2011;81(2):339-45.

28. Vandecaveye V, Dirix P, De Keyzer F, Op de Beeck K, Vander Poorten V, Hauben $E$, et al. Diffusion-weighted magnetic resonance imaging early after chemoradiotherapy to monitor treatment response in head-and-neck squamous cell carcinoma. Int J Radiat Oncol Biol Phys. 2012;82(3):1098-107.

29. Jacobs L, Intven M, van Lelyveld N, Philippens $M$, Burbach M, Seldenrijk K, et al. Diffusion-weighted MRI for early prediction of treatment response on preoperative Chemoradiotherapy for patients with locally advanced rectal Cancer: a feasibility study. Ann Surg. 2016;263(3):522-8.

30. Ceulemans G, Voordeckers M, Farrag A, Verdries D, Storme G, Everaert H. Can 18-FDG-PET during radiotherapy replace post-therapy scanning for detection/demonstration of tumor response in head-and-neck cancer? Int J Radiat Oncol Biol Phys. 2011;81(4):938-42.

31. Hur H, Tulina I, Cho MS, Min BS, Koom WS, Lim JS, et al. Biomarker-based scoring system for prediction of tumor response after preoperative Chemoradiotherapy in rectal Cancer by reverse transcriptase polymerase chain reaction analysis. Dis Colon Rectum. 2016;59(12):1174-82.

32. Elshafeey N, Hassan I, Zinn PO, Colen RR. From K-space to nucleotide: insights into the Radiogenomics of brain tumors. Top Magnet Reson Imaging : TMRI. 2017;26(1):33-41.

33. Sala E, Mema E, Himoto $Y$, Veeraraghavan $H$, Brenton JD, Snyder A, et al. Unravelling tumour heterogeneity using next-generation imaging: radiomics, radiogenomics, and habitat imaging. Clin Radiol. 2017;72(1):3-10.

\section{Publisher's Note}

Springer Nature remains neutral with regard to jurisdictional claims in published maps and institutional affiliations.

Ready to submit your research? Choose BMC and benefit from:

- fast, convenient online submission

- thorough peer review by experienced researchers in your field

- rapid publication on acceptance

- support for research data, including large and complex data types

- gold Open Access which fosters wider collaboration and increased citations

- maximum visibility for your research: over $100 \mathrm{M}$ website views per year

At $\mathrm{BMC}$, research is always in progress.

Learn more biomedcentral.com/submissions 